\title{
CONFORTO TÉRMICO DE BOVINOS DA RAÇA NELORE A PASTO SOB DIFERENTES CONDIÇÕES DE SOMBREAMENTO E A PLENO SOL ${ }^{1}$
}

\author{
FRANCIELE C. NAVARINI ${ }^{2}$, ELCIO S. KLOSOWSKI ${ }^{3}$, ALESSANDRO T. CAMPOS ${ }^{4}$, \\ RODRIGO DE A. TEIXEIRA ${ }^{5}$, CLÉCIO P. ALMEIDA ${ }^{6}$
}

\begin{abstract}
RESUMO: Principalmente em regiões de clima quente, a produção bovina sob condições de pasto pode ser melhorada com o uso de sombra natural para minimizar o estresse por calor. Desse modo, o objetivo do presente estudo foi avaliar o efeito do estresse térmico por meio de índices de conforto térmico na produção bovina sob diferentes condições de sombreamento natural. Este estudo foi conduzido na região oeste do Estado do Paraná, no período de janeiro a fevereiro de 2007. O delineamento experimental foi o inteiramente casualizado, com três tratamentos constituídos de árvores formando pequenos bosques, árvores isoladas e condição não sombreada. A cada um desses tratamentos foi submetido um grupo de dez animais da raça Nelore (repetições). Os valores diários de velocidade do vento, temperatura de globo negro, temperatura de bulbo seco e temperatura de bulbo molhado foram registrados a cada três horas a partir de 9 às $18 \mathrm{~h}$. A temperatura da superfície corporal animal foi registrada com a mesma frequência. Para cada tratamento, com base nessas medidas, foram calculados o índice de temperatura e umidade (ITU), índice de temperatura de globo e umidade (ITGU) e a carga térmica de radiação (CTR). Os valores de ITU variaram de 70 a 87, os de ITGU entre 73 e 93 e os de CTR entre 450 e $672 \mathrm{~W} \mathrm{~m}^{-2}$. O ambiente que proveu melhores condições térmicas para os animais foi constituído por pequenos bosques de árvores de Guajuvira.
\end{abstract}

PALAVRAS-CHAVE: bioclimatologia, conforto térmico, gado de corte.

\section{THERMAL COMFORT OF NELORE BOVINE IN PASTURE UNDER SEVERAL LIGHTING CONDITIONS}

\begin{abstract}
Mainly in hot climate conditions, the beef cattle production under pasture can be improved with the use of natural shade to minimize the heat stress. Therefore, the objective of the present study was to evaluate the effect of the thermal stress using thermal comfort indexes on the beef cattle production under different conditions of natural shade. This study was carried out in the West region of the State of Paraná in January and February 2007. The experimental design was completely randomized with three treatments constituted of trees forming small forests, isolated trees and not shaded condition. Each one of these treatments was submitted a group of ten animals of the Nelore breed (replications). The daily values of wind speed, black globe, dry bulb temperature and wet bulb temperature were registered every each three hour, from 9 a.m. to 6 p.m. The temperature of the animal body surface was also registered with the same frequency. For each treatment, based in these measured, the temperature and humidity index (THI), black globe and humidity index (BGHI) and the radiant heat load (RHL) were calculated. The THI values varied from 70 to 87 , from 73 to 93 for the BGHI and from 450 to $672 \mathrm{~W} \mathrm{~m}^{-2}$ for the RHL. The environment that provided the best thermal conditions for the animals was constituted by small forests of Guajuvira trees.
\end{abstract}

KEYWORDS: beef cattle, bioclimatology, thermal comfort.

\footnotetext{
${ }^{1}$ Trabalho de qualificação do primeiro autor e de conclusão de curso do último autor, financiado com recursos da UNIOESTE.

${ }^{2}$ Zootecnista, Mestre/UNIOESTE/PPZ, Cooperativa Agrícola Mista Rondon - Copagril/Marechal Candido Rondon-PR, Fone: (0XX45) 3284.7500, franvarini@ copagril.com.br

${ }^{3}$ Prof. Adjunto, Centro de Ciências Agrárias, UNIOESTE, Marechal Candido Rondon - PR, elciosk@unioeste.br

${ }^{4}$ Prof. Adjunto, Departamento de Engenharia, UFLA, Lavras - MG, campos@ deg.ufla.br.

${ }^{5}$ Prof. Adjunto, Departamento de Zootecnia, UEPG, Ponta Grossa - PR, rodrigo_fcav@ hotmail.com

${ }^{6}$ Zootecnista, autônomo.

Recebido pelo Conselho Editorial em: 14-10-2008
}

Aprovado pelo Conselho Editorial em: 27-8-2009

Eng. Agríc., Jaboticabal, v.29, n.4, p.508-517, out./dez. 2009 


\section{INTRODUÇÃO}

O Brasil possui o maior rebanho bovino comercial do mundo, com mais de 207 milhões de cabeças, destacando-se não somente pelo tamanho do rebanho, mas também pelo potencial de crescimento (IBGE, 2007). Mas, para que essa produção continue a crescer, vários fatores devem ser considerados pelo produtor para não prejudicar ou causar danos aos animais e à atividade pecuária.

Fatores como disponibilidade de água, sombreamento, temperatura corporal do animal, comportamentos em condições de temperaturas diferentes, que afetam diretamente as trocas térmicas de calor sensível (condução, convecção cutânea e radiação) e as perdas de calor latente (evaporação cutânea) para o ambiente, podem levar o animal ao estresse térmico. Esse estresse ocorre caso o equilíbrio térmico entre o animal e o ambiente não for conseguido, o que pode ocasionar graves problemas, tanto na produção, como na reprodução animal.

A interação animal e ambiente deve ser considerada quando se busca maior eficiência na exploração pecuária, pois as diferentes respostas do animal às peculiaridades de cada região são determinantes no sucesso da atividade. Assim, a correta identificação dos fatores que influem na vida produtiva do animal, como o estresse imposto pelas flutuações estacionais do meio ambiente, permite ajustes nas práticas de manejo dos sistemas de produção, possibilitando oferecer sustentabilidade e viabilidade econômica. Dessa forma, o conhecimento das variáveis climáticas, sua interação com os animais e as respostas comportamentais, fisiológicas e produtivas são preponderantes na adequação do sistema de produção aos objetivos da atividade (NEIVA et al., 2004).

Segundo BACCARI JÚNIOR (2001), a temperatura interna de um animal é mais elevada e vai diminuindo até sua periferia (pele e pelos), formando gradiente térmico do interior para a parte mais externa do corpo. A temperatura do pelame é um dos principais parâmetros na avaliação de dissipação do calor pelos animais (SANTOS et al., 2005).

As preocupações sobre conforto ambiental e bem-estar animal estão cada vez maiores no âmbito público, e os sistemas de produção de proteína animal estão procurando atender a essas exigências. Nesse sentido, os sistemas de produção devem propiciar condições adequadas de criação, visando a aperfeiçoar a produção e a atender a essas demandas de mercado. No sistema de produção de gado a pasto, o sombreamento natural é um recurso que contribui para o provimento de bem-estar dos animais (MARTINS, 2001).

Diante de tais considerações, o presente trabalho foi conduzido com o objetivo de avaliar o ambiente térmico para bovinos de corte, criados sob diferentes condições de sombreamento natural, por meio de índices de conforto térmico.

\section{MATERIAL E MÉTODOS}

O experimento foi realizado em uma propriedade particular que explora a bovinocultura de corte, denominada Sítio São Francisco, situada no município de Diamante D’Oeste, Estado do Paraná.

Diamante D'Oeste localiza-se à latitude $24^{\circ} 56^{\prime} 34^{\prime \prime}$ sul e à longitude $54^{\circ} 6^{\prime} 11^{\prime \prime}$ oeste, estando à altitude de $521 \mathrm{~m}$. De acordo com a geomorfologia dos solos, identificam-se no município as seguintes características: Latossolo roxo, com a presença de solo com textura média e afloramentos de rocha (pedregozidade).

Segundo a classificação de Köeppen, o tipo climático predominante na região é o Cfa - clima subtropical úmido, com temperatura média no mês mais frio inferior a $18^{\circ} \mathrm{C}$ e temperatura média do mês mais quente acima de $22^{\circ} \mathrm{C}$, sendo a temperatura média anual de $20^{\circ} \mathrm{C}$ (IAPAR, 2008).

O experimento foi realizado durante o verão, no período compreendido entre os meses de janeiro e fevereiro do ano de 2007. Foram utilizadas 30 fêmeas Nelore, com massa corporal entre 
219 e $390 \mathrm{~kg}$, de aproximadamente 15 meses, selecionadas a partir de 330 animais. Grupos de dez animais foram selecionados aleatoriamente, por meio de sorteio de suas identificações, buscando maior representatividade das características dos animais, como sua massa, mantendo-se o padrão comercial da propriedade. Um grupo de dez animais foi criado em piquete com área de 6 hectares, no qual as árvores formavam pequenos bosques, predominando espécies arbóreas como a Guajuvira (Patagonula americana L.), que, segundo LOREZI (2002), trata-se de uma planta pioneira, decídua e heliófita, característica de floresta latifoliada. A altura varia de 10 a $25 \mathrm{~m}$, diâmetro de tronco de 70 a $80 \mathrm{~cm}$ e copa piramidal e densa. As folhas são simples, glabras e com 3 a $6 \mathrm{~cm}$ de comprimento.

O segundo grupo de dez animais foi criado em piquete com área de 3,5 hectares, com sombreamento proporcionado por árvores individuais, como a Goiabeira (Psidium guajava) e a laranjeira (Citrus X sinensis (L.) Osbeck). A goiabeira, de acordo com LOREZI (2002), é uma planta semidecídua, heliófita e característica e preferencial de Mata Pluvial Atlântica. A altura varia de 3 a $6 \mathrm{~m}$, com tronco tortuoso de 20 a $30 \mathrm{~cm}$ de diâmetro. As folhas são simples, com comprimento de 8 a $12 \mathrm{~cm}$ e largura de 3 a $6 \mathrm{~cm}$. Já a laranjeira, como descreve TASSARO (2009), é uma árvore de porte médio, podendo atingir até $8 \mathrm{~m}$ de altura, tronco com casca castanho-acinzentada, copa densa e de formato arredondado. As folhas apresentam textura firme e bordos arredondados, com comprimento de aproximadamente $10,2 \mathrm{~cm}$.

Os demais foram criados em piquete com área de 3 hectares, sem disponibilidade de sombra. Em todos os piquetes, havia disponibilidade de água de bebida e era cultivado o capim Estrela-africana (Cynodon plectostachyus).

O ambiente térmico a pasto das três condições foi avaliado a partir da temperatura de bulbo seco, temperatura de bulbo molhado, temperatura do ponto de orvalho, temperatura de globo negro e velocidade do vento. As medidas desses elementos do clima foram tomadas em intervalos de três horas a partir das $9 \mathrm{~h}$ até às $18 \mathrm{~h}$, durante 27 dias.

Para as medidas de temperatura de globo negro, foram utilizados termômetros de mercúrio da marca Incoterm ${ }^{\circledR}$, com escala de -10 a $+60{ }^{\circ} \mathrm{C}$ e com resolução de $0,5^{\circ} \mathrm{C}$, inseridos em esferas de polietileno pintadas de preto fosco. Para a determinação das propriedades psicrométricas do ar úmido, foram utilizados psicrômetros da marca Incoterm ${ }^{\circledR}$, com escala de -10 a $+50{ }^{\circ} \mathrm{C}$ e resolução de $1{ }^{\circ} \mathrm{C}$. A velocidade do vento foi medida por anemômetro de hélice da marca Instrutherm ${ }^{\circledR}$, modelo AD-155, com resolução de $0,1 \mathrm{~m} \mathrm{~s}^{-1}$ e escala de 0,8 a $30 \mathrm{~m} \mathrm{~s}^{-1}$.

\section{Avaliação das condições de conforto térmico}

Para cada horário e situação de sombreamento, foram calculados o índice de temperatura e umidade, o índice de temperatura de globo e umidade e a carga térmica de radiação.

Todas essas medidas foram tomadas à altura de aproximadamente $1,10 \mathrm{~m}$, que corresponde à altura do centro de massa de bovino de corte.

O índice de temperatura e umidade (BACCARI et al., 1983) foi determinado pela eq.(1):

$$
\mathrm{ITU}=\mathrm{tbs}+0,36 \text { tpo }-41,2
$$

em que,

ITU - índice de temperatura e umidade, adimensional;

tbs - temperatura do bulbo seco, ${ }^{\circ} \mathrm{C}$, e

tpo - temperatura do ponto de orvalho, ${ }^{\circ} \mathrm{C}$.

O índice de temperatura de globo e umidade (BUFFINGTON et al., 1981) foi estimado conforme eq.(2) apresentada abaixo:

$$
\text { ITGU }=\operatorname{tgn}+0,36 \text { tpo }-41,5
$$

em que, 
ITGU - índice de temperatura de globo e umidade, adimensional, e tgn - temperatura do globo negro, ${ }^{\circ} \mathrm{C}$.

Para determinar a carga térmica de radiação, foi utilizada a eq.(3), proposta por ESMAY (1978):

$\mathrm{CTR}=\sigma(\mathrm{TRM})^{4}$

em que,

CTR - carga térmica de radiação, $\mathrm{Wm}^{-2}$;

$\sigma$ - constante de Stefan-Boltzmann $5,67.10^{-8} \mathrm{Wm}^{-2} \mathrm{~K}^{-4}$, e

TRM - temperatura radiante média, $\mathrm{K}$.

$$
\mathrm{TRM}=100 \sqrt[4]{2,51 \sqrt{\mathrm{v}}(\mathrm{Tgn}-\mathrm{Tbs})+\left(\frac{\mathrm{Tgn}}{100}\right)^{4}}
$$

em que,

$\mathrm{v}$ - velocidade do vento, $\mathrm{m} \mathrm{s}^{-1}$;

Tgn - temperatura de globo negro, K, e

Tbs - temperatura de bulbo seco, K.

\section{Temperatura da superficie corporal}

A temperatura da superfície corporal foi observada nos mesmos horários da coleta dos elementos meteorológicos. As medidas foram tomadas por meio de termômetro sem contato, por infravermelho com mira a laser, da marca Raytek ${ }^{\circledR}$, modelo MT4, com escala de -18 a $275{ }^{\circ} \mathrm{C}$ e resolução de $0,1{ }^{\circ} \mathrm{C}$. As medidas foram sempre tomadas na região do dorso dos animais que se encontravam, no momento da observação, sob sombra natural ou expostos a pleno sol.

\section{Delineamento experimental e análise estatística}

O delineamento experimental utilizado foi o inteiramente casualizado, com três tratamentos constituídos por pequenos bosques, árvores isoladas e pleno sol, sendo cada animal uma repetição.

Para a análise de conforto térmico ambiente, foi empregado o esquema de parcelas subdivididas, com três tratamentos constituídos pelos tipos de sombreamento. Os dias de observação corresponderam às parcelas, e os horários de observação como as subparcelas.

Para a análise estatística, foi utilizado o teste de Tukey, a 5\% de probabilidade, por meio do software SAS (SAS INSTITUTE, 1998).

\section{RESULTADOS E DISCUSSÃO}

Durante o período experimental, as médias diárias de temperatura do ar foram de $26,9^{\circ} \mathrm{C}$, $28,6^{\circ} \mathrm{C}$ e $30,5^{\circ} \mathrm{C}$ para os tratamentos de pequenos bosques, árvores isoladas e pleno sol, respectivamente. Esse último valor superou os níveis divulgados pelo IAPAR (2008), que informa que o trimestre mais quente para a região de Diamante D'Oeste ocorre entre os meses de dezembro e fevereiro, cujas temperaturas médias do ar variam entre 27 e $28^{\circ} \mathrm{C}$. De acordo com o mesmo órgão, a umidade relativa do ar média anual varia entre 75 e $80 \%$. Apesar de a temperatura do ar ser elevada às $15 \mathrm{~h}$ no tratamento de pleno sol $\left(33^{\circ} \mathrm{C}\right)$, a umidade relativa do ar apresentou-se dentro da faixa de conforto $(61 \%)$. BAETA \& SOUZA (1997) consideram que, para bovinos, as melhores condições climáticas seriam de temperatura entre 10 e $27{ }^{\circ} \mathrm{C}$, umidade relativa do ar de 60 a $70 \%$ e velocidade dos ventos de 5 a $8 \mathrm{~km} \mathrm{~h}^{-1}$, possibilitando maior perda de calor.

Em todos os tratamentos, a velocidade do vento manteve-se abaixo da faixa ideal para bovinos, tendo pico máximo de 4,35 $\mathrm{km}_{\text {hora }}{ }^{-1}$ às $12 \mathrm{~h}$, no tratamento de árvores isoladas.

As médias dos índices de conforto térmico para os diferentes tratamentos estão apresentadas na Tabela 1. Para o ITU, o valor médio do tratamento de pleno sol chegou a 80, o que indica 
possível condição de estresse térmico para os animais. No caso do ITGU, o valor médio no mesmo tratamento foi de 84 , mostrando que os animais se encontravam em situação de desconforto térmico.

Com base na Tabela 1, verificou-se que a condição térmica para o ITU variou de branda (72 a 78) a moderada (79 a 88), segundo a classificação de HAHN \& MADER (1997) para o ambiente térmico de bovinos. Geralmente, esses valores não causam problemas para animais saudáveis, mas podem acarretar redução na taxa de ganho de peso.

Apesar de os índices de conforto calculados para todos os tratamentos indicarem possível condição de desconforto para os animais, houve diferença significativa entre os mesmos (Tabela 1), principalmente quando comparados os piquetes com árvores formando pequenos bosques e a pleno sol, demonstrando que o sombreamento a pasto proporciona ambiente térmico mais confortável para bovinos de corte.

Dentro das estratégias de sombreamento utilizadas, observa-se que os maiores valores de ITU, em todos os tratamentos, foram verificados no horário das $15 \mathrm{~h}$, o que pode ter ocasionado maior estresse aos bovinos nesse horário, em relação aos demais (Figura 1). Contudo, no início da manhã e no final da tarde, foram observados menores valores desse índice, efeito provocado pelos menores valores de temperatura, consequência da menor disponibilidade energética ao meio.

Os resultados do índice de temperatura e umidade obtidos neste trabalho assemelham-se aos encontrados por MARQUES et al. (2005), observando o comportamento de touros, embora em condições de confinamento e alojados individualmente ou em grupos. De acordo com esses autores, foram observados valores de ITU de 75 e 81, para os períodos manhã e tarde, respectivamente, que indicam que os animais se encontravam em condição de alerta e perigo, podendo ocasionar até a morte. Contudo, HAHN (1999), avaliando as condições térmicas para bovinos em regiões norte-americanas, afirma que, mesmo para valores de ITU acima de 75 , pode não haver prejuízos à produção, desde que as temperaturas noturnas sejam mais amenas.

$\mathrm{Na}$ Tabela 1, para os valores médios diários de ITGU, foi encontrada diferença significativa entre os tratamentos. Em todos os tratamentos, de acordo o National Weather Service - USA, citado por BAÊTA (1985), os animais encontravam-se em situação de perigo (ITGU de 79 a 84), o que pode ocasionar baixo rendimento. No tratamento formado por árvores constituindo pequenos bosques, a condição térmica foi amenizada pelas árvores que reduzem a incidência de radiação solar, mantendo mais elevada a umidade do ar e menor a temperatura do ar.

Os valores de ITGU maiores que 81, encontrados para os tratamentos árvores isoladas e pleno sol, de acordo com o que sugere FERNANDES (2005), caracterizam estresse térmico. De acordo com esse autor, a partir desses valores, os animais apresentariam redução no consumo de matéria seca total. Essa redução seria de $22 \%$, comparados aos animais submetidos a ambiente que proporcionou conforto térmico $(\mathrm{ITGU}=65)$.

TABELA 1. Médias dos índices de conforto térmico para as condições de bosque (PB), árvores isoladas (AI) e pleno sol (PS), durante os meses de janeiro e fevereiro de 2007, em Diamante D'Oeste - PR. Thermal comfort indexes for the conditions of small forests (PB), isolated trees (AI) and not shaded condition (PS) in the West region of the State of Paraná, Brazil, from January and February 2007.

\begin{tabular}{cccc}
\hline \multirow{2}{*}{ Tratamentos } & \multicolumn{3}{c}{ Médias } \\
\cline { 2 - 4 } & ITU & ITGU & CTR $\left(\mathrm{Wm}^{-2}\right)$ \\
\hline PB & $76 \mathrm{a}$ & $79 \mathrm{a}$ & $508 \mathrm{a}$ \\
AI & $78 \mathrm{~b}$ & $82 \mathrm{~b}$ & $543 \mathrm{~b}$ \\
PS & $80 \mathrm{c}$ & $84 \mathrm{c}$ & $571 \mathrm{c}$ \\
\hline
\end{tabular}

Médias seguidas de mesma letra na coluna não diferem entre si, pelo teste de Tukey (5\%).

ITU - índice de temperatura e umidade; ITGU - índice de temperatura de globo e umidade, e CTR - carga térmica de radiação. 


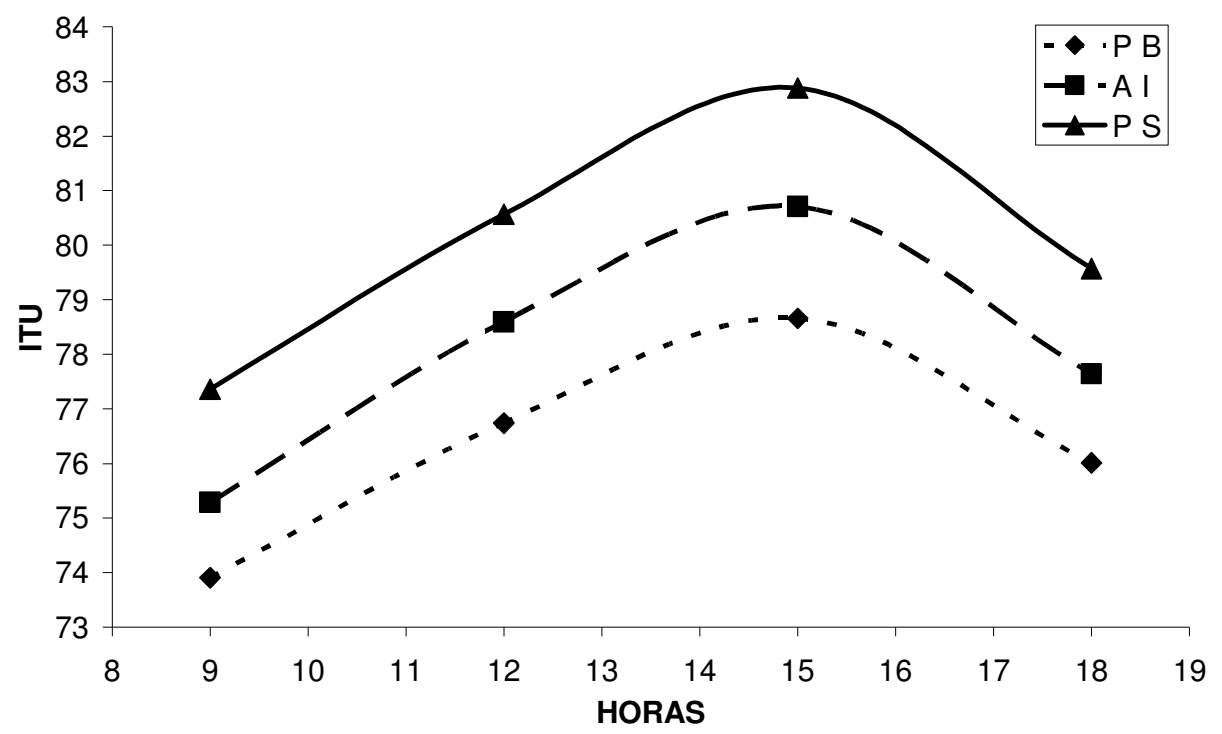

FIGURA 1. Valores do índice de temperatura e umidade (ITU) para os diferentes horários do dia na condição de pequenos bosques (PB), árvores isoladas (AI) e pleno sol (PS), durante os meses de janeiro e fevereiro de 2007, em Diamante D'Oeste - PR. The temperature and humidity index (THI) values for the conditions of small forests (PB), isolated trees (AI) and not shaded condition (PS) in the West region of the State of Paraná, Brazil, from January and February 2007.

Na Figura 2, podem ser observados os valores de ITGU para os tratamentos e os horários do dia. As curvas seguem variação semelhante às do ITU, uma vez que o ITGU é calculado substituindo-se, nas equações de ITU, o termo referente à temperatura de bulbo seco pela temperatura de globo negro (BACCARI JÚNIOR, 2001).

Os valores de ITGU foram maiores em todos os tratamentos para o período das $15 \mathrm{~h}$, e para o tratamento a pleno sol atingiu pico de 88, considerado situação de emergência (Figura 2). Esse aumento do ITGU já era esperado, pois as maiores temperaturas do ar são observadas entre $12 \mathrm{~h} \mathrm{e}$ $15 \mathrm{~h}$.

Valores semelhantes foram constatados por TITTO (2006), que avaliou o efeito do ITGU sob sombra natural, sombra artificial e sem disponibilidade de sombra sobre o comportamento de touros da raça Simental a pasto. Esse autor observou maiores registros de ITGU a partir das $12 \mathrm{~h}$ e, em todos os tratamentos, caracterizou-se condição de "emergência", segundo a classificação do National Weather Service - USA.

Como pode ser observado na Figura 2, o maior valor de ITGU foi registrado às $15 \mathrm{~h}$ no tratamento de pleno sol, enquanto SOUZA et al. (2007) obtiveram esse mesmo valor de ITGU na sombra, e de 97 ao sol, quando avaliaram bovinos da raça Sindi no semiárido paraibano. Mesmo nas condições estressantes daquele ambiente, os parâmetros fisiológicos de frequência respiratória e temperatura retal mantiveram-se dentro dos limites considerados normais para bovinos.

Para a CTR, o maior valor médio também foi observado no tratamento a pleno sol (Tabela 1), com valor de $571 \mathrm{~W} \mathrm{~m}^{-2}$. Para o tratamento de pequenos bosques, não houve grande variação nos valores de CTR no período compreendido entre 9 e $18 \mathrm{~h}$.

Na Figura 3, foi apresentada a variação de CTR nos diferentes horários do dia para os tratamentos pequenos bosques, árvores isoladas e pleno sol. Nota-se que os valores máximos são observados às $15 \mathrm{~h}$, considerando que, na sua estimativa, empregam-se valores que representam a temperatura do ar, radiação solar e das superfícies adjacentes e a movimentação do ar. 


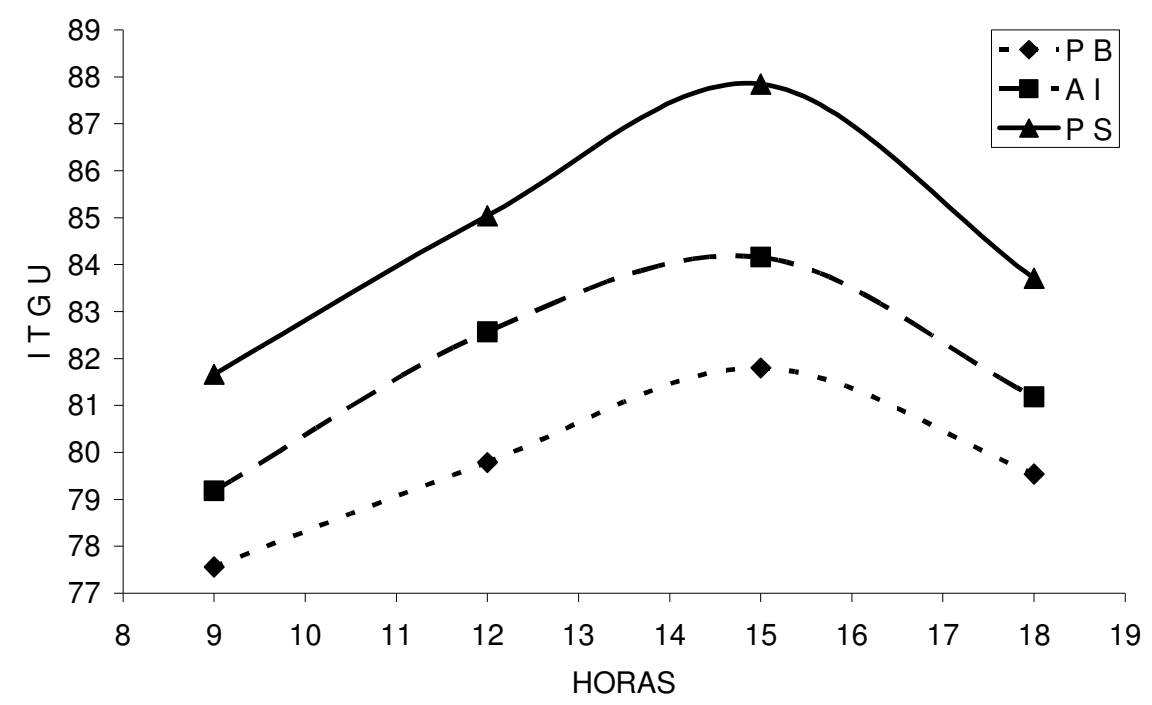

FIGURA 2. Valores do índice de temperatura de globo e umidade (ITGU) para os diferentes horários do dia, na condição de pequenos bosques (PB), árvores isoladas (AI) e pleno sol (PS), durante os meses de janeiro e fevereiro de 2007, em Diamante D'Oeste - PR. The Black globe humidity index (BGHI) values for the conditions of small forests (PB), isolated trees (AI) and not shaded condition (PS) in the West region of the State of Paraná, Brazil, from January and February 2007.

O ambiente proporcionado por pequenos bosques de Guajuvira foi o que apresentou melhores condições de conforto aos animais, devido ao fato de que as árvores funcionam como uma barreira, evitando a incidência de radiação direta na área sob a copa. BAETA \& SOUZA (1997) corroboram essa informação, a partir da premissa de que as árvores também transformam energia solar em energia química latente pelo processo de fotossíntese, o que reduz a parcela de energia destinada ao aquecimento do ar. Em relação ao tratamento pleno sol, o sombreamento observado em pequenos bosques provocou redução média de aproximadamente $11 \%$ na CTR.

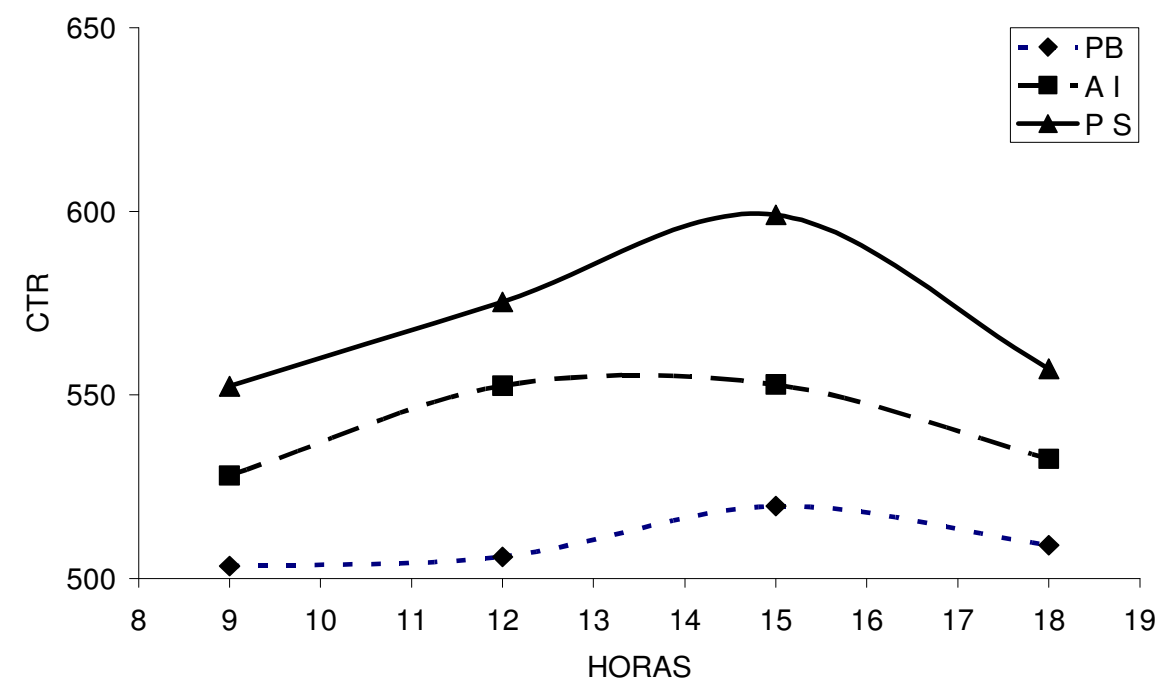

FIGURA 3. Valores da carga térmica de radiação (CTR) para os diferentes horários do dia, na condição de pequenos bosques (PB), árvores isoladas (AI) e pleno sol (PS), durante os meses de janeiro e fevereiro de 2007, em Diamante D'Oeste - PR. The radiant heat load (RHL) values for the conditions of small forests (PB), isolated trees (AI) and not shaded condition (PS) in the West region of the State of Paraná, Brazil, from January and February 2007. 
Os valores de CTR para pequenos bosques de Guajuvira observados na Figura 3, cuja média foi de $508 \mathrm{Wm}^{-2}$ (Tabela 1), assemelham-se aos obtidos por MARTINS (2001), que, avaliando a qualidade térmica do sombreamento natural durante o verão, no período entre 12 e $16 \mathrm{~h}$, obteve CTR média de $500 \mathrm{~W} \mathrm{~m}^{-2}$ para a espécie Sapateiro (Pera glabrata Baill.), uma árvore cuja copa apresenta maior densidade de folhas e, portanto, realiza maior interceptação da radiação solar, o que lhe confere melhor qualidade térmica. $\mathrm{O}$ mesmo autor, para a espécie Orelha-de-Preto (Enterolobium contortisiliquum Morong), observou CTR média de 549,4 $\mathrm{W} \mathrm{m}^{-2}$.

GUISELINI et al. (1999) também constataram que os valores de CTR dependem da qualidade do sombreamento proporcionado pela espécie arbórea em estudo. Os autores observaram para as espécies arbóreas Santa Bárbara (Melia azedarach), Leucena (Leucaena leucocephala) e Chapéu-de-Sol (Terminalia catappa), os valores médios de CTR entre $12 \mathrm{~h}$ e $14 \mathrm{~h}$, de $521 ; 588$ e $512 \mathrm{~W} \mathrm{~m}^{-2}$, respectivamente. $\mathrm{O}$ valor obtido para Leucena demonstrou qualidade de sombra inferior às demais espécies por possuir a copa larga e as folhas delgadas, características morfológicas que propiciaram maior incidência de radiação solar. Os menores valores de CTR observados para as espécies Santa Bárbara e Chapéu-de-Sol devem-se à copa mais densa e com folhas menores para a primeira e folhas maiores para a segunda, o que lhes confere qualidade térmica igual.

\section{Temperatura da superfície corporal}

Ao analisar a temperatura superficial corporal dos animais na Tabela 2, pode-se observar que os maiores valores foram verificados para o tratamento a pleno sol, o que indica possível condição de desconforto para os animais.

Nota-se que, apesar de os valores médios de temperatura da superfície corporal para os diferentes tratamentos se manterem muito próximos, fato explicado por se tratar de animais homeotérmicos, que mantêm a temperatura corporal constante, houve diferença significativa entre os mesmos pelo teste de Tukey, a $5 \%$ de probabilidade. $\mathrm{O}$ valor de $35,2{ }^{\circ} \mathrm{C}$ de temperatura da superfície corporal encontrado para o tratamento a pleno sol foi superior aos valores médios encontrados para os tratamentos de pequenos bosques e árvores isoladas, que foram de 34,3 e $34,7^{\circ} \mathrm{C}$, respectivamente.

Esses resultados demonstram que a exposição a pleno sol, devido à incidência de radiação solar, elevou a temperatura da superfície corporal de $0,9^{\circ} \mathrm{C}$, comparado com o tratamento de pequenos bosques. Esse valor pode ser considerado apreciável, por ser média, e por se tratar de animais homeotérmicos. A carga de energia radiante incidente no animal, em regiões tropicais, pode ser maior que três vezes o total de calor endógeno produzido pelo próprio animal (MARTINS, 2001). Com isso, a absorção da radiação solar pelo animal e a temperatura ambiente podem aumentar a produção de calor metabólico, resultando em desconforto térmico (ENCARNAÇÃO, 1989).

TABELA 2. Valores mínimo, máximo e médio de temperatura da superfície corporal de bovinos da raça Nelore para a condição de pequenos bosques (PB), árvores isoladas (AI) e pleno sol (PS), durante os meses de janeiro e fevereiro de 2007, em Diamante D'Oeste - PR. Average, minimum and maximum values of the body surface temperature of the Nelore breed for the conditions of small forests (PB), isolated trees (AI) and not shaded condition (PS) in the West region of the State of Paraná, Brazil, from January and February 2007.

\begin{tabular}{cccc}
\hline \multirow{2}{*}{ Tratamentos } & \multicolumn{3}{c}{ Temperatura da Superfície Corporal $\left({ }^{\circ} \mathrm{C}\right)$} \\
\cline { 2 - 4 } & Mínima & Máxima & Média \\
\hline PB & 32,8 & 36,0 & $34,3 \mathrm{a}$ \\
A I & 33,0 & 36,5 & $34,7 \mathrm{~b}$ \\
P S & 33,4 & 37,0 & $35,2 \mathrm{c}$ \\
\hline
\end{tabular}

Médias seguidas de mesma letra na coluna não diferem entre si, pelo teste de Tukey (5\%). 
SANTOS et al. (2005), ao avaliarem e compararem a temperatura da pele de vacas e de bezerros das raças Pantaneira e Nelore, durante um ano, na região do Pantanal Sul Matogrossense, obtiveram valores médios de temperatura da pele das vacas de $33,6{ }^{\circ} \mathrm{C}$ e $32,9{ }^{\circ} \mathrm{C}$, e a de bezerros de $34,2{ }^{\circ} \mathrm{C}$ e $35,6{ }^{\circ} \mathrm{C}$, respectivamente. Os autores conjecturam que as temperaturas da pele de ambas as raças foram menores para as vacas, comparadas aos bezerros, devido ao fato de que o ganho e a perda de calor dependem do tamanho corporal.

\section{CONCLUSÕES}

Para as condições em que o experimento foi conduzido, a melhor condição térmica foi observada em ambiente de sombreamento proporcionado por pequenos bosques constituídos de árvores de Guajuvira, comparada à proporcionada por árvores isoladas de Goiabeira e Laranjeira, e para exposição a pleno sol.

Os valores médios de temperatura da superfície corporal para pleno sol, pequenos bosques e árvores isoladas foram de $35,2^{\circ} \mathrm{C}, 34,3^{\circ} \mathrm{C}$ e $34,7^{\circ} \mathrm{C}$, respectivamente, e corroboram os resultados de condição térmica mais confortável proporcionada por pequenos bosques, em que se utilizaram árvores de Guajuvira.

\section{REFERÊNCIAS}

BACCARI JÚNIOR, F. Manejo Ambiental da vaca leiteira em climas quentes. Londrina: Universidade Estadual de Londrina, 2001. 142 p.

BACCARI JÚNIOR, F.; JOHNSON, H.D.; HAHN, G.L. Environmental heat effects on growth, plasma $\mathrm{T}_{3}$ and postheat compensatory effects on Holstein calves. Proceedings of the Society for Experimental Biology and Medicine, Okland, v.173, n.3, p.312-318, 1983.

BAÊTA, F.C. Responses of lactating dairy cows to the combined effects of temperature, humidity and wind velocity in the warm season. 1985. 218 f. Thesis (Ph.D.) - University of Missouri, Columbia, 1985.

BAÊTA, F.C.; SOUZA, C.F. Ambiência em edificações rurais: conforto animal. Viçosa - MG: Universidade Federal de Viçosa, 1997. 246 p.

BUFFINGTON, D.E.; COLLAZO-AROCHO, A.; CANTON, G.H.; PITT, D.; THATCHER, W.W.; COLLIER, R.J. Black globe-humidity index (BGHI) as comfort equation for dairy cows. Transaction of the ASAE, St. Joseph, v.24, n.3, p.711-714, 1981.

ENCARNAÇÃO, R.O. Estresse e produção animal. In: CICLO INTERNACIONAL DE PALESTRAS SOBRE BIOCLIMATOLOGIA ANIMAL, 1989, Botucatu. Anais... Jaboticabal: FUNEP, 1989. p.111-129.

ESMAY, M.L. Principles of animal environment. Westport: AVI, 1978. 358 p. (Environmental engineering in agriculture and food series)

FERNANDES, A.C. Efeito do estresse térmico sobre a seleção de dieta por bovinos. $2005.90 \mathrm{f}$. Dissertação (Mestrado em Medicina Veterinária) - Faculdade de Medicina Veterinária e Zootecnia, Universidade de São Paulo, Pirassununga, 2005.

GUISELINI, C.; DA SILVA, I.J.O.; PIEDADE, S.M. Avaliação da qualidade do sombreamento arbóreo no meio rural. Revista Brasileira de Engenharia Agrícola e Ambiental, Campina Grande, v.3, n.3, p.380-384, 1999.

HAHN, G.L. Dynamic responses of cattle to thermal heat loads. Journal of Animal Science, Champaign, v.77, Supp. 2, p.10-20, 1999.

HAHN, G.L.; MADER, T.L. Heat waves in relation to thermoregulation, feeding behavior and mortality of feedlot cattle. In: PROCEEDINGS OF THE INTERNATIONAL LIVESTOCK 
ENVIRONMENT SYMPOSIUM MINNEAPOLIS, 5., 1997, Minneapolis. Proceedings... St. Joseph: ASAE, 1997. p.563-567.

IAPAR. INSTITUTO AGRONÔMICO DO PARANÁ. Disponível em: <http:www.iapar.br> Acesso em: 5 nov. 2008.

IBGE. INSTITUTO BRASILEIRO DE GEOGRAFIA E ESTATÍSTICA. Disponível em: <http:www.ibge.com.br>. Acesso em: 25 maio 2007.

LORENZI, H. Árvores brasileiras: manual de identificação e cultivo de plantas arbóreas do Brasil. 2.ed. Nova Odessa: Instituto Plantarum, 2002. v.2, 368 p.

MARQUES, J.A.; MAGGIONI, D.; ABRAHAO, J.J.S.; GUILHERME, E.; BEZERRA, G.A.; LUGAO, S.M.B. Comportamento de touros jovens em confinamento alojados isoladamente ou em grupo. Archivos Latinoamericanos de Producción Animal, Maracaibo, v.13, n.3, p. 97-102, 2005.

MARTINS, J.L. Avaliação da qualidade térmica do sombreamento natural de algumas espécies arbóreas, em condições de pastagem. 2001. 99 f. Dissertação (Mestrado em Água e Solo) Universidade Estadual de Campinas, Campinas, 2001.

NEIVA, J.N.M.; TEIXEIRA, M.; TURCO, H.N.; OLIVEIRA, S.M.P.; MOURA, A. de A.A.N. Efeito do estresse climático sobre os parâmetros produtivos e fisiológicos de ovinos Santa Inês mantidos em confinamento na região litorânea do Nordeste do Brasil. Revista Brasileira de Zootecnia, Viçosa - MG, v.33, n.3, p.668-678, 2004.

SANTOS, S.A.; MCMANUS, C.; SOUZA, G.S.; SORIANO, B.M.A.; SILVA, R.A.M.S.; COMASTRI FILHO, J.A.; ABREU, U.G.P.; GARCIA, J.B. Variações da temperatura corporal e da pele de vacas e bezerros das raças Pantaneira e Nelore no pantanal. Archivos de Zootecnia, Córdoba, v.54, n.206-207, p.238, 2005.

SAS INSTITUTE. SAS/STAT User's guide: statistics. Version 6.12. $4^{\text {th }}$ ed. Cary, 1998. 842 p.

SOUZA, B.B.; SILVA, R.M.N.; MARINHO, M.L.; SILVA, G.A.; SILVA, E.M.N.; SOUZA, A.P. Parâmetros fisiológicos e índice de tolerância ao calor de bovinos da raça sindi no semiárido Paraibano. Ciência e Agrotecnologia, Lavras, v.31, n.3, p.883-888, 2007.

TASSARO, H. A biblioteca virtual do estudante brasileiro. Disponível em: $<$ http/www.bibvirt.futuro. usp.br/index.php/textos/didaticos e tematicos/frutas no brasil/laranja>. Acesso em: 26 maio 2009.

TITTO, C.G. Comportamento de touros da raça Simental a pasto com recurso de sombra e tolerância ao calor. 2006. 54 f. Dissertação (Mestrado em Qualidade e Produtividade Animal) Faculdade de Zootecnia e Engenharia de Alimentos, Universidade de São Paulo, Pirassununga, 2006. 